\title{
Ascorbic Acid Increases the Thyrotropin-Releasing Hormone Content of Hypothalamic Cell Cultures
}

\author{
Christopher C. Glembotski, ${ }^{\star}$ Scott Manaker, $\dagger, \ddagger,{ }^{1}$ Andrew Winokur, ${ }^{\star}, \ddagger$ and Thomas R. Gibson \\ Departments of *Pharmacology, †Biology, and \$Psychiatry, University of Pennsylvania, Philadelphia, \\ Pennsylvania 19104
}

\begin{abstract}
Thyrotropin-releasing hormone (TRH) is one of many COOHterminal $\alpha$-amidated neuropeptides. Recent work with the intermediate pituitary has indicated that ascorbate is a required cofactor for the COOH-terminal $\alpha$-amidation of $\alpha$-melanotropin. This is consistent with the ascorbate requirement of an enzyme found in pituitary and hypothalamus capable of converting peptides with a COOH-terminal glycine (-X-Gly) to $\alpha$-amidated molecules $\left(-\mathrm{H}-\mathrm{NH}_{2}\right)$. Thus, it has been proposed that COOH-terminal glycine-extended TRH (TRH-Gly) may be the direct precursor to TRH. In the present study, primary hypothalamic cultures supplemented with ascorbate for $7 \mathrm{~d}$ contained two- to threefold more TRH immunoactivity (amide-specific) than cultures maintained without ascorbate. A dose-response experiment indicated that $20 \mu \mathrm{M}$ ascorbate was capable of producing $50 \%$ of the maximum observable increase in culture TRH immunoactivity; this concentration is similar to the $K_{\mathrm{m}}$ value for ascorbate uptake obtained in adrenal chromaffin and pituitary cells. A stereoisomer of ascorbate, D-isoascorbate, was also capable of producing an increase in TRH immunoactivity, but oxidized ascorbate was not. Recent studies have shown that the amidation enzyme from pituitary is capable of utilizing both L-ascorbate and D-isoascorbate but is incapable of utilizing oxidized ascorbate. The culture extracts were analyzed further by reversed-phase high-performance liquid chromatography; the increased TRH immunoactivity observed in extracts of cultures maintained in ascorbate comigrated with standard synthetic TRH. TRH- and TRH-Gly specific antisera were used to measure the quantities of these peptides: When cultures were maintained for $7 \mathrm{~d}$ in the absence of ascorbate, the TRH to TRHGly ratio was 8-fold less than the TRH to TRII-Gly ratio in cultures maintained in the presence of $250 \mu \mathrm{M}$ ascorbate. These results suggest that ascorbate is a required cofactor for the COOH-terminal $\alpha$-amidation of TRH and that the direct precursor to TRH in the rat hypothalamus may possess a $\mathrm{COOH}$ terminal glycine residue.
\end{abstract}

During the past 10 years a large number of peptides, many of which were originally characterized in endocrine tissues, have been localized to the CNS. In order to characterize the factors that regulate their production, the biosynthetic pathways of both endocrine and neuropeptides must be determined. Over the last

\footnotetext{
Received Sept. 9, 1985; revised Nov. 25, 1985; accepted Nov. 25, 1985.

This work was supported by NIH Grants NS20396, NS18332, and MSTP S-T32-GM07170, by NIMH Grant RSDA MH00044, and by a B.R.S.G. SO7RR-05415-22 awarded by the Biomedical Research Support Grant Program, Division of Research Resources, NIH. We wish to thank Susan Devlin and Pam Knight for expert technical assistance, Paul Shields for the preparation and analysis of diketoascorbate, and Gary Wildey for enlightening scientific discussions.

Correspondence should be addressed to Christopher C. Glembotski, Department of Pharmacology/G3, School of Medicine, University of Pennsylvania, 36th Street and Hamilton Walk, Philadelphia, PA 19104.

'Present address: Department of Medicine, Boston City Hospital, Boston, MA. Copyright (C) 1986 Society for Neuroscience 0270-6474/86/061796-07\$02.00/0
}

15 years many aspects of endocrine peptide biosynthesis have been elucidated. In part, these studies have been facilitated by the relatively high levels of peptides found in endocrine tissues. However, since neuropeptides are present in the CNS in such low levels (1000- to 10,000-fold lower than endocrine peptides), detailed biosynthetic studies are relatively few (Bloom, 1983; Brownstein, 1983; Douglass et al., 1984; Hökfelt et al., 1984; Iverson, 1983; Krieger, 1983; Richter et al., 1984). In the study reported here, we have been able to extend some of our recent findings on endocrine peptide biosynthesis to studies of an important neuropeptide, thyrotropin-releasing hormone (TRH).

Thyrotropin-releasing hormone (pyro-Glu-His-Pro- $\mathrm{NH}_{2}$ ) was the first hypothalamic releasing factor to be isolated and sequenced (Boler et al., 1969; Burgus et al., 1969). Subsequently, it was found to be widely distributed throughout the CNS (Brownstein et al., 1974; Winokur et al., 1974) and shown to exert many non-hypophysiotropic effects (Jackson, 1982). However, attempts to characterize the mechanism of biosynthesis of TRH have largely been unsuccessful for several reasons, including its low levels in the CNS, small size, and blocked $\mathrm{NH}_{2}-$ and $\mathrm{COOH}$-terminals. Several early studies demonstrated relatively low levels of incorporation of radioactivity into TRH either in vivo or in organ culture (McKelvy, 1974, 1983; McKelvy et al., 1975; Reichlin and Mitnick, 1971). Rupnow et al. (1979) demonstrated the possible existence of a larger molecular weight substance derived from frog brain that-on trypsinization, chemical amidation, and pyro-glutamyl formation-was converted into material possessing TRH immunoactivity and bioactivity. However, studies demonstrating the incorporation of radioactivity into TRH by cultured cells have been few, and the convincing demonstration of the formation of authentic TRH from a biosynthetic precursor has not been performed.

The precursor and/or gene sequences of many neuro- and endocrine peptides have been elucidated (Douglass et al., 1984). From these studies the amino acid sequences of peptide precursors have been inferred; single or paired basic amino acids generally flank the sequence of the mature peptide, and $\mathrm{COOH}$ terminal glycine extended peptides (-X-Gly) have been proposed as the direct precursors to $\alpha$-amidated molecules $\left(-\mathrm{X}-\mathrm{NH}_{2}\right)$. $\mathrm{Re}$ cently, a partial sequence of the precursor for TRH from frog skin was reported, and these data indicate that pro-TRH has at least 3 repeats of the following sequence: -Basic-Basic-Gln-HisPro-Gly-Basic-Basic (Richter et al., 1984). This inferred peptide sequence suggests that the direct precursor to TRH is COOHterminally glycine extended.

Several groups have recently reported an enzymatic activity involved in the $\mathrm{COOH}$-terminal $\alpha$-amidation of peptides. Bradbury et al. (1982) have demonstrated the existence of an enzyme in ovine pituitary that converts model peptide substrates possessing COOH-terminal glycine residues to the corresponding $\alpha$-amidated products. A similar enzyme, localized to the secretory vesicles of rat anterior, intermediate, and posterior pituitary 
tissue, as well as hypothalamus, has been shown to require ascorbate, $\mathrm{CuSO}_{4}$, and molecular oxygen for optimal activity (Eipper et al., 1983b; Emeson, 1984). The enzyme has been named peptidyl $\alpha$-amidating monooxygenase (PAM), and the pituitary enzyme has been shown in vitro to convert $\mathrm{COOH}$-terminally glycine-extended forms of $\alpha$-melanocyte-stimulating hormone ( $\alpha \mathrm{MSH})$ to the $\alpha$-amidated peptides in an ascorbate-dependent fashion (Glembotski, 1985). Several recent reports have suggested that a similar activity in brain homogenates is capable of converting synthetic radiolabeled TRH-Gly to material with chromatographic properties similar to that of authentic TRH (Gomez et al., 1984; Husain and Tate, 1983; Kizer et al., 1984); the ascorbate dependence of the reaction was not determined in those studies. Recent biosynthetic experiments have shown that in primary culture, intermediate pituitary cells produce $\mathrm{COOH}$-terminal glycine-extended forms of $\alpha \mathrm{MSH}$ in the $\mathrm{ab}$ sence of ascorbate, while in the presence of ascorbate, $\alpha$-amidated $\alpha \mathrm{MSH}$ is produced (Eipper et al., 1985; Glembotski, 1984).

Although the $\alpha$-amidation of neuropeptides is a common modification and is required in most cases for optimal bioactivity, a detailed examination of the mechanism of this modification in ncurons has not bccn pcrformed. Since PAM is present in neural tissue, the COOH-terminal $\alpha$-amidation of many neuropeptides may occur by a mechanism similar to that observed for $\alpha$-MSH in the intermediate pituitary. Thus, ascorbate would be a required cofactor for the $\alpha$-amidation of neuropeptides, such as the hypothalamic releasing factors. In support of this hypothesis, we report the existence of TRH and TRH-Gly in rat hypothalamus and evaluate the effects of ascorbate on the levels of these two peptides in primary cultures of fetal rat hypothalamus.

\section{Materials and Methods}

\section{Cell culture}

Hypothalamic tissue was dissected from $20 \mathrm{~d}$ fetal Sprague-Dawley rats and stored in sterile air-compatible Dulbecco's modified Eagle's medium during the dissection period (maximum time, $2 \mathrm{hr}$ ). Each hypothalamus was bisected and incubated in a mixture of collagenase (Type 2), hyaluronidase, BSA (fraction V), and DNase with stirring, as previously described for pituitary cell dissociation (Mains and Eipper, 1979). The tissue was stirred for $20-30 \mathrm{~min}$ at $37^{\circ} \mathrm{C}$, followed by further mechanical dissociation by trituration using a plastic automatic pipet tip. After the dissociation of the tissue, the cells were collected by sedimentation, filtered through $125 \mu \mathrm{M}$ fiber mesh (Small Parts, Inc.), collected again by sedimentation, and resuspended in the desired volume of DMEM containing $10 \%$ fetal bovine serum and $100 \mu \mathrm{g} / \mathrm{ml}$ kanamycin sulfate. The cells derived from 5 to 9 fetal animals were plated onto protamine-coated $35 \mathrm{~mm}$ Costar culture dishes in a total volume of 4 $\mathrm{ml}$. In initial studies, cultures were prepared using a previously published mechanical dissociation procedure (Faivre-Bauman et al., 1980) or a previously published procedure involving dissociation with papain (Canick et al., 1977). Culture medium was replaced at $2 \mathrm{~d}$ intervals. Cells were collected from dishes by scraping into $200 \mu \mathrm{l}$ of PBS. The dishes were then rinsed twice with $500 \mu \mathrm{l}$ of absolute methanol and the suspensions homogenized with a ground glass homogenizer ( $5-10$ passes by hand). The homogenate $(1200 \mu l)$ was centrifuged to remove precipitated material, and the supernatant was vacuum evaporated.

\section{$T R H$ radioimmunoassays}

TRH radioimmunoassays (RIA) were performed with an antibody prepared by the method of Bassiri and Utiger (1972). This previously characterized antibody cross-reacts less than $2 \%$ as well with TRH-OH,

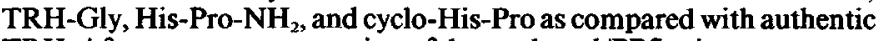
TRH. After vacuum evaporation of the methanol/PBS mixture, extracts were redissolved in a total volume of $200 \mu 1$ of $50 \mathrm{~mm}$ phosphate buffer (pH 7.4) containing $2.5 \mathrm{mg} / \mathrm{ml} \mathrm{BSA}$. Five serial twofold dilutions of each sample were prepared in the same buffer; each sample was then incubated for $14 \mathrm{hr}$ with the TRH antiserum (1:50,000 dilution) and ${ }^{125}$ I-TRH trace that had been prepared as described below. Bound TRH was separated from free TRH using a subsequent $4 \mathrm{hr}$ incubation with second antibody. The midpoint of the assay was 10-15 pg TRH/tube and allowed the detection of as little as $5 \mathrm{pg}$ TRH.

\section{Preparation of TRH-Gly antiserum}

TRH-Gly was custom-synthesized by Bachem (Torrance, CA) and coupled to BSA using bis-diazotized benzidine, as previously described for TRH (Bassiri and Utiger, 1972). The linkage efficiency was established as $70 \%$ by using trace quantities of ${ }^{125}$ I-TRH-Gly during cross-linking. Rabbits were injected with the equivalent of $68 \mu \mathrm{g}$ of TRH-Gly conjugated to BSA; the initial immunization was performed with an equalvolume mixture of conjugate and complete Freund's adjuvant. Booster injections were performed at approximately 4 week intervals using incomplete instead of complete Freund's adjuvant. Serum samples were obtained 2 weeks after each boost and tested for the ability to bind ${ }^{125} \mathbf{I}-$ TRH-Gly and ${ }^{125}$ I-TRH. Eight rabbits were immunized, and 2 animals displayed positive titers for TRH-Gly 2 weeks after the first boost. Only one of the animals (Glynda) had a titer sufficient for further use in radioimmunoassays. TRH-Gly radioimmunoassays were performed essentially as described for TRH utilizing ${ }^{125}$ I-TRH-Gly as the trace and various TRH-related peptides for displacement.

\section{Preparation of ${ }^{225} I-T R H$ and ${ }^{25} I-T R H-G l y$}

Iodinations were performed with the chloramine $T$ method previously described for TRH (Bassiri and Utiger, 1972). The iodinated peptides were purified on ODS cartridges (Waters) as previously described (Bennett et al., 1981; Court et al., 1983). The differential elution of the unlabeled and iodinated TRH-related peptides allowed for the isolation of relatively high specific activity trace.

\section{Reversed-phase HPLC analysis of TRH}

The TRH immunoactivity in culture and tissue extracts was analyzed by reversed-phase high-performance liquid chromatography (RP-HPLC) on a $\mathrm{C}_{18} \mu$ Bondapak column ( $3.7 \mathrm{~mm} \times 30 \mathrm{~cm}$, Waters) using a $0.1 \%$ trifluoroacetic acid (TFA) buffer system and gradient elution with acetonitrile, similar to a system previously described (Bennett et al., 1981; Court et al., 1983). Briefly, buffer $A$ was $0.1 \%$ TFA and buffer $B$ was $0.1 \%$ TFA containing $80 \%$ acetonitrile. After evaporation, extracts were redissolved in $300 \mu \mathrm{l}$ of buffer $\mathrm{A}$, applied to the column, and chromatographed at a flow rate of $1 \mathrm{ml}$ of buffer $A / \mathrm{min}$. After $5 \mathrm{~min}$, gradient elution was initiated; the gradient progressed from $0-35 \%$ buffer $B$ in $60 \mathrm{~min}$. Fractions $(0.5 \mathrm{ml})$ were collected beginning at sample application. The following peptides eluted with the following retention times: cyclo-His-Pro, $13 \mathrm{~min}$; TRH, $26 \mathrm{~min}$; TRH-Gly, $28 \mathrm{~min}$; TRH-OH, $30 \mathrm{~min}$. Although His, His-Pro, and Glu-TRH (Glu-His-Pro- $\mathrm{NH}_{2}$ ) eluted before the gradient was initiated, these peptides were separated from one another. The average recovery of TRH immunoactivity from the RP-HPLC analyses was $87 \%$.

\section{Results}

\section{Extraction and tissue dissociation procedures}

Several methods of tissue extraction are frequently used for the preparation of TRH-containing samples. We compared one of these, the PBS/methanol extraction procedure of Winokur and Utiger (1974), with a procedure we routinely use for the extraction of pro-adrenocorticotropic hormone/endorphin-related peptides from pituitary (Eipper et al., 1985; Glembotski, 1984). The latter procedure entails homogenization of tissue in $5 \mathrm{~N}$ acetic acid containing $0.3 \mathrm{mg} / \mathrm{ml}$ phenylmethylsulfonyl fluoride (PMSF) and $0.1 \%$ 2-mercaptoethanol, followed by either lyophilization or vacuum evaporation. The major disadvantage of the acetic acid extraction was the apparent TRH-like immunoactivity that was contributed by the extraction solution components. All 3 components contributed apparent immunoactivity, such that the acetic acid extraction buffer blank possessed about 5 or 6 times more apparent TRH than did the methanol extraction buffer blank. The PBS/methanol extraction buffer background contributed $25 \mathrm{pg}$ of apparent TRH immunoactivity, or about one-fourth of the average value obtained with only one $20 \mathrm{~d}$ fetal rat hypothalamus (average, $96 \mathrm{pg}$ TRH). 


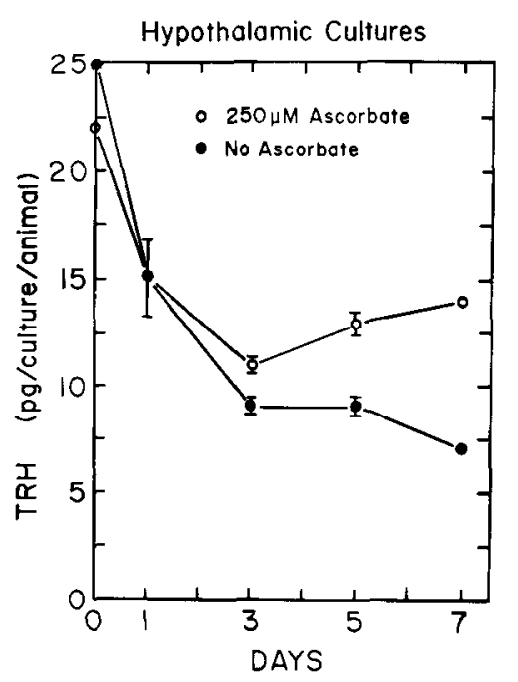

Figure 1. Effects of ascorbate on TRH immunoactivity in hypothalamic cultures: time course. Cells were prepared from the hypothalamic tissue from 71 (with ascorbate) and 57 (without ascorbate) fetal rats (20 d), plated, and maintained in DMEM containing $10 \%$ fetal bovine serum, as described in Materials and Methods. Culture medium was replaced at 2,4 , and $6 \mathrm{~d}$; we have previously shown that reduced ascorbate is stable to auto-oxidation in the presence of the added fetal bovine serum (Glembotski, 1984; P. P. Shields et al., unpublished observations). Duplicate cultures were analyzed for TRH immunoactivity at 1 , 3 , and $5 \mathrm{~d}$. The TRH immunoactivity in each extract was normalized to content per hypothalamus; cultures with ascorbate $(O)$ contained cells prepared from the equivalent of 8.8 hypothalamus, whereas cultures without ascorbate (๑) were prepared from 7 hypothalamus each. This data represents the results from one of 2 experiments; both produced similar results.

Thus, because of the relatively low background contribution of the PBS/methanol buffer and because methanol has been shown to inhibit TRH degradative enzymes (Bassiri and Utiger, 1974; Winokur and Utiger, 1974), this was the extraction medium chosen for further studies.

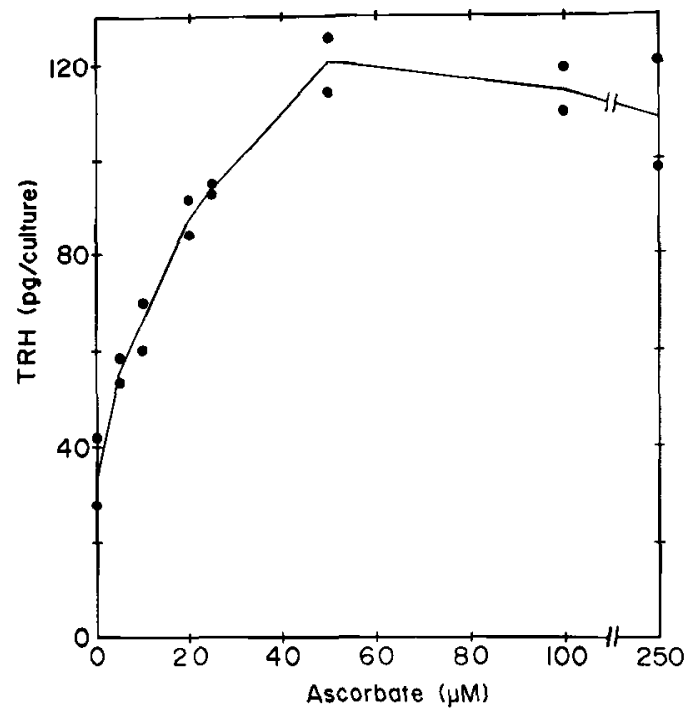

Figure 2. Effect of varied ascorbate on culture TRH immunoactivity. Each dish contained cells prepared from 5 to 6.5 fetal rats and was maintained for $7 \mathrm{~d}$ in medium containing $10 \%$ fetal bovine serum and various levels of ascorbate. Culture medium was replaced as described in legend to Figure 1. Each point represents the immunoreactive TRH content of a single culture; each evaporated culture extract was dissolved in phosphate buffer ( $\mathrm{pH} 7.4$ ) containing $2.5 \mathrm{mg} / \mathrm{ml} \mathrm{BSA}$ and 5 serial 2-fold dilutions were prepared and immunoassayed.

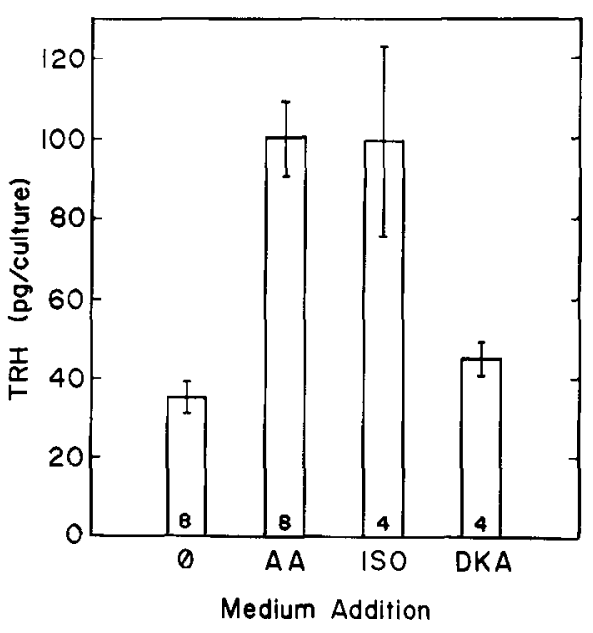

Figure 3. Effect of various forms of ascorbate on culture TRH immunoactivity. Cultures were prepared from 5 to 6.5 fetal rats each and were maintained for $7 \mathrm{~d}$ in medium containing $10 \%$ fetal bovine serum and $250 \mu \mathrm{M}$ ascorbate $(A A)$, D-isoascorbate $(I S O)$, or diketoascorbate $(D K A)$. The diketoascorbate was prepared by bubbling oxygen through a $1 \mathrm{~mm}$ ascorbate solution ( $\mathrm{pH} \mathrm{3.6)}$ ) for $6 \mathrm{~min}$ followed by raising the pH to 7.4 and incubating at $37^{\circ} \mathrm{C}$ for $60 \mathrm{~min}$ (Tolbert and Ward, 1982). The oxidation of the ascorbate was confirmed by RP-HPLC analysis as previously described (Diliberto et al., 1983). The number of cultures assayed after each treatment $(n)$ is shown within each histogram. The SEM was calculated for each treatment. Analysis of variance revealed significant differences among the means $\left(F_{3,20}=11.81 ; p<0.0001\right)$. Post hoc Newman-Keuls comparisons demonstrated both isoascorbate and ascorbate treatments to result in significantly greater culture TRH levels than both the control $(\mathscr{\varnothing )}$ and diketoascorbate treatments.

Since most of the experiments required the dissection of 50 80 fetal animals, we investigated whether the tissue TRH levels were stable during storage of the tissue in medium at room temperature during the $2 \mathrm{hr}$ dissection period. There was no significant difference in TRH content between hypothalamic tissue extracted immediately on removal from the animal and tissue stored in medium for $2 \mathrm{hr}$ before extraction (data not shown).

We were also interested in maximizing the recovery of TRHcontaining cells during the dissociation procedure. Several dissociation procedures for fetal hypothalamic tissue have been reported. These include the use of papain as a proteolytic enzyme to facilitate cell dissociation (Canick et al., 1977) and mechanical procedures that depend primarily on trituration with fire-polished pasteur pipets for dissociation (Faivre-Bauman et al., 1980). In our previous work with pituitary cell dissociation, we have used a mixture of collagenase, hyaluronidase, and DNase followed by trypsin (Glembotski, 1984; Mains and Eipper, 1979). Thus, for hypothalamic dissociations we compared these 3 procedures for recovery of TRH immunoactivity. The collagenase procedure was modified by omission of the trypsin step. The papain, mechanical, and collagenase procedures resulted in the recovery of 8,40 , and $68 \%$ of the initial TRH immunoactivity, respectively. Thus, the collagenase dissociation procedure was used in all further experiments.

The plating efficiency was determined by maintaining the cultures at $37^{\circ} \mathrm{C}$ in $5 \% \mathrm{CO}_{2}$ for $15 \mathrm{hr}$ to allow attachment to the dish, and then extracting and comparing the culture TRH immunoactivity with that of the dissociated cells before plating. After the $15 \mathrm{hr}$ incubation, $61 \%$ of the TRH immunuactivity originally plated was recovered. Thus, after $15 \mathrm{hr}$ in culture, $40 \%(68 \times 61 \%)$ of the TRH immunoactivity originally in the tissue was recovered. 


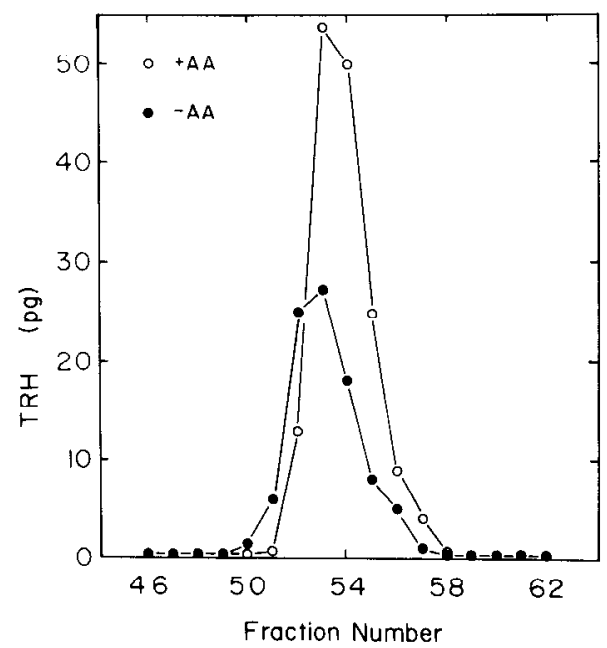

Figure 4. Effect of ascorbate on culture TRH immunoactivity: RPHPLC analysis. Two cultures, each prepared from 8 fetal hypothalamus, were maintained for $7 \mathrm{~d}$ with $(0)$ or without (0) $200 \mu \mathrm{M}$ ascorbate. The cultures were extracted and analyzed by RP-HPLC as described in Materials and Methods. The elution position of synthetic TRH (fraction $53,26.5 \mathrm{~min}$ ) was determined in a parallel analysis. The recovery of TRH immunoactivity was approximately $85 \%$.

TRH immunoactivity in cultures supplemented with ascorbate

To establish the importance of ascorbate in the biosynthesis of $\alpha$-amidated neuropeptides, the level of TRH immunoactivity present in hypothalamic cultures with and without ascorbate was determined. Since the TRH antiserum cross-reacts poorly with TRH-Gly, RIA with this antiserum could be used as an initial measure of the effect of ascorbate on the levels of authentic, $\alpha$-amidated TRH in cultures. Culture TRH immunoactivity decreased during the initial $3 \mathrm{~d}$ in all cultures. In cultures without ascorbate, the TRH immunoactivity continued to decrease for the subsequent $4 \mathrm{~d}$ (Fig. 1). In contrast, cultures supplemented with $250 \mu \mathrm{M}$ ascorbate possessed increasing amounts of TRH immunoreactivity as a function of time from day 3-7 (Fig. 1). Four experiments of this type have shown that at $7 \mathrm{~d}$, cultures supplemented with $250 \mu \mathrm{M}$ ascorbate possess 2to 3 -fold more TRH immunoactivity than those maintained in ascorbate-free conditions. In preliminary experiments the ascorbate-supplemented cultures have shown a continued increase in TRH immunoreactivity through day 9 , whereas cultures lacking ascorbate possess less TRH immunoactivity at day 9 than at day 3. Thus, since TRH immunoactivity was steadily increasing at $7 \mathrm{~d}$ in culture, this time period was chosen for experiments designed to probe further the nature of this response to ascorbate.

\section{Ascorbate dose-response}

To evaluate the levels of ascorbate required for increased culture TRH immunoactivity a dose-response experiment was carried out: cultures were maintained for $7 \mathrm{~d}$ in medium supplemented with various amounts of ascorbate. There was a clear ascorbate concentration dependence in culture TRH immunoactivity showing the half-optimal ascorbate concentration to be about $20 \mu \mathrm{M}$ (Fig. 2). The maximal TRH immunoactivity was observed when cultures were supplemented with $50 \mu \mathrm{M}$ ascorbate (3-fold greater than with no ascorbate) and seemed to remain relatively constant throughout the remainder of the concentration range up to $250 \mu \mathrm{M}$ ascorbate. In a previous study it has been shown that cultured intermediate pituitary cells produce $\alpha$-amidated $\alpha \mathrm{MSH}$ in response to medium ascorbate levels between 25 and $50 \mu \mathrm{M}$ (Glembotski, 1984).

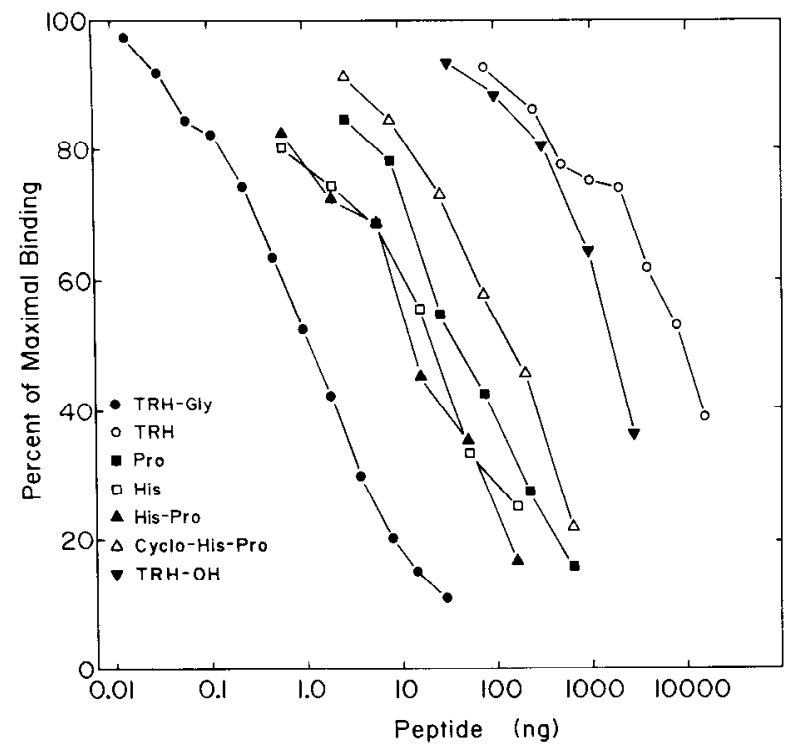

Figure 5. Characterization of TRH-Gly antiserum Glynda. Immunoassays using the TRH-Gly antiserum were performed as described in Materials and Methods. In each case, approximately 18,000 dpm of ${ }^{125}$ I-TRH-Gly was used as the trace and various unlabeled peptides related to TRH were used as competing compounds. Total binding of ${ }^{125}$ I-I'KH-Gly was between 30 and $40 \%$, and the nonspecific binding was less than $3 \%$.

\section{Various forms of ascorbate}

Since the fully reduced form of L-ascorbate is the major form of the cofactor in the circulation and in cells (Hornig, 1975), we were able to establish further that the increase in TRH immunoactivity in ascorbate-supplemented cultures was physiologically relevant by testing fully oxidized ascorbate and a stereoisomer of $\mathrm{I}$-ascorbate, D-isoascorbate, as cofactors. Oxidized ascorbate (diketoascorbate) at $250 \mu \mathrm{M}$ was not capable of producing an increase in culture TRH immunoactivity (Fig. 3); this is consistent with the observation that the oxidized form of ascorbate is not assimilated by pituitary (P. P. Shields, T. R. Gibson, and C. C. Glembotski, unpublished observations) and adrenal medullary cells in culture (Diliberto et al., 1983). D-Isoascorbate was also capable of producing an equivalent increase in culture TRH immunoactivity to that observed with ascorbate, consistent with the observation that $\mathrm{D}$-isoascorbate can support $\alpha$-amidation of $\alpha \mathrm{MSH}$ in intermediate pituitary primary cells (Glembotski, 1984).

\section{$H P L C$ verification of culture $T R H$}

RP-HPLC was used to characterize further the TRH immunoactivity in culture extracts. All of the culture immunoactivity comigrated with authentic TRH and the 2- to 3-fold increase in immunoactivity observed in crude culture extracts was reflected by a similar increase observed after HPLC analysis (Fig. 4).

\section{TRH-Gly antiserum Glynda}

The increase in TRH immunoactivity with ascorbate supplementation could be due to an inhibition of secretion by the cofactor, or to the ascorbate-dependent conversion of TRH-Gly to TRH. To distinguish between these possibilities, an antiserum was prepared to TRH-Gly to enable the direct determination of levels of this peptide in culture extracts. At a dilution of 1:400, the $\mathrm{IC}_{50}$ for antiscrum Glynda was betwecn 400 and $800 \mathrm{pg}$ TRH-Gly/tube (Fig. 5). The relative cross-reactivities for various peptides and amino acids related to TRH are summarized in Table 1 . As expected for an antiserum raised to 


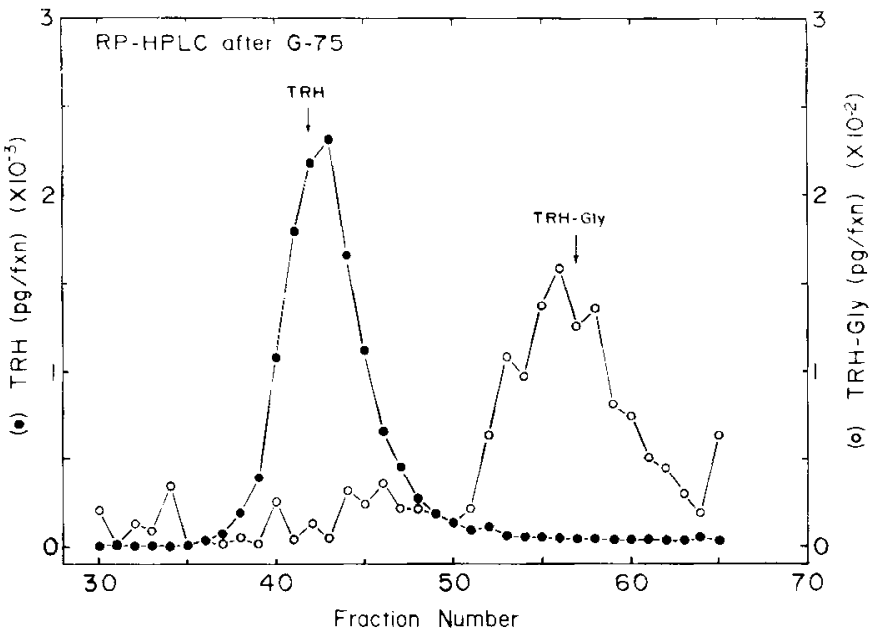

Figure 6. RP-HPLC characterization of TRH and TRH-Gly. Forty rat hypothalami from adult animals were extracted, chromatographed on a Sephadex G-75 column in $10 \%$ formic acid $/ 0.1 \mathrm{mg} / \mathrm{ml} \mathrm{BSA}$, and the TRH-related material was evaporated and chromatographed by RPHPLC as described in Materials and Methods. Fraction collection (0.5 ml) was initiated 5 min after sample application. The arrows mark the elution positions of standard synthetic TRH and TRH-Gly as localized by $A_{214}$ in a different analysis. Synthetic TRH and TRH-Gly eluted at approximately 26 and $28 \mathrm{~min}$, respectively.

a small peptide, there is a high degree of selectivity. Compared to TRH-Gly, TRH is only $0.01 \%$ as potent as TRH-Gly at displacing ${ }^{125}$ I-TRH-Gly from the antiserum (Table 1). Other peptides related to TRH that are suspected metabolites were also tested (Table 1, Fig. 5). These metabolites might be present in cell and tissue extracts, but since they all have relatively low cross-reactivity with the antiserum, TRH-Gly levels could be determined using relatively crude samples. For routine TRHGly immunoassays, extracts were purified on ODS cartridges.

Levels of TRH and TRH-Gly immunoactivity in hypothalamic tissue extracts

A recent developmental study has demonstrated a continual increase in hypothalamic TRH content in rats as a function of both pre- and postnatal development. At $21 \mathrm{~d}$ gestation, $7 \mathrm{~d}$ postnatal, and in the adult, the hypothalamus has been reported to contain 41,458 , and $2696 \mathrm{pg}$ TRH immunoactivity per structure (Lamberton et al., 1984). In the present study, rats of var-

\section{Table 1. Specificity of the TRH-Gly antiserum Glynda}

\begin{tabular}{ll} 
Peptide & $\begin{array}{l}\text { Percent cross- } \\
\text { reactivity }\end{array}$ \\
\hline TRH-Gly & 100 \\
His-Pro & 9 \\
His & 5 \\
Pro & 2.5 \\
Cyclo-His-Pro & 0.75 \\
Pyro-Glu-His-Pro-Gly-NH & 0.09 \\
Glu-His-Pro-NH & \\
Pro-NH & 0.09 \\
TRH-OH & 0.08 \\
TRH & 0.07 \\
\hline
\end{tabular}

Immunoassays were performed as described in Materials and Methods. Various unlabeled peptides and amino acids were used to compete with the binding of ${ }^{125}$ I-TRH-Gly to antiserum Glynda. Percent cross-reactivity $=\left[\mathrm{IC}_{50}\right.$ of TRH-Gly/ $\mathrm{IC}_{\text {50 }}$ of competitor] $\times 100$.
Table 2. Levels of TRH and TRH-Gly in hypothalamic tissue

\begin{tabular}{lccc} 
Animal agc & TRH (pg/hypo) & $\begin{array}{c}\text { TRH-Gly } \\
(\mathrm{pg} / \mathrm{hypo})\end{array}$ & $\begin{array}{c}\text { TRH/ } \\
\text { TRH-Gly }\end{array}$ \\
\hline Fetal & $52.5 \pm 9.0$ & $44.5 \pm 0.8$ & 1.2 \\
Neonatal & $318.9 \pm 12.5$ & $64.5 \pm 4.9$ & 4.9 \\
Adult & $2788.9 \pm 146.7$ & $106.4 \pm 3.6$ & 26.2
\end{tabular}

Conditions: 123 fetal ( $20 \mathrm{~d}$ gestation), 13 neonatal $(7 \mathrm{~d}$ old), and 20 adult (150$200 \mathrm{gm}$ ) rats were sacrificed, the hypothalamic tissue removed, and extracted as described in Materials and Methods. After ODS cartridge purification, the extracts were evaporated and anlalyzed for TRH and TRH-Gly immunoreactivities. Three aliquots equivalent to $1 / 2 s$ (TRH) or $1 / 5$ (TRH-Gly) of each extract were assayed for peptide content; values shown are averages \pm SEM. In a parallel group of extracts, the overall recoveries of ${ }^{125}$ I-TRH and ${ }^{125}$ I-TRH-Gly werc 87 and $92 \%$, respectivcly.

ious ages were used to determine whether the hypothalamic content of TRH-Gly varies in a similar manner with development. As previously reported, the TRH levels increased as a function of age; however, the TRH-Gly levels remained relatively unchanged. There were similar quantities of TRH and TRH-Gly immunoactivity in hypothalamic extracts from $20 \mathrm{~d}$ prenatal animals, while in the adult the ratio of TRH/TRH-Gly was $26 / 1$ (Table 2). This may be due to developmental differences in the expression of the gene for TRH and the gene encoding the amidation enzyme, PAM. Alternatively, the hypothalamic cells in the fetal and newborn animal may be less ascorbate-responsive than adult hypothalamic cells, with respect to peptidc amidation.

\section{Effect of ascorbate on levels of TRH and TRH-Gly immunoactivity in cultured hypothalamic cells}

In a preliminary experiment, the levels of TRH and TRH-Gly immunoactivity in cultured cells maintaincd with or without ascorbate were determined. Thirty cultures were prepared from a total of 120 fetal hypothalami and maintained (half with and half without ascorbate) for $7 \mathrm{~d}$. Interestingly, the levels of TRH and TRH-Gly in the extracts responded oppositely to the presence of the cofactor in the medium. Cultures supplemented with ascorbate contained $106 \mathrm{pg}$ TRH-Gly immunoactivity and 100 pg TRH immunoactivity. Cultures maintained without the cofactor contained $310 \mathrm{pg}$ TRH-Gly immunoactivity and $35 \mathrm{pg}$ of TRH immunoactivity. ${ }^{2}$ These results support the hypothesis that TRH-Gly is an alternate end product that is formed in hypothalamic cells in the absence of ascorbate.

\section{HPLC analysis of TRH and TRH-Gly immunoactivities}

To verify further the identification of TRH- and TRH-Gly immunoactivities in hypothalamic extracts, reversed-phase- and ion-exchange-HPLC analyses were performed. Adult hypothalamic tissue was extracted, submitted to ODS cartridge purification, and then chromatographed on a $\mathrm{C}_{18} \mu$ Bondapak HPLC column in a TFA/acetonitrile solvent system (see Materials and Methods). TRH and TRH-Gly immunoactivities eluted with retention times identical to the synthetic peptides (Fig. 6). The recoveries of both TRH and TRH-Gly from the tissue were greater than $75 \%$. The ratio of TRH to TRH-Gly as determined after RP-HPLC was similar to that determined in the crude extracts by RIA. This indicated that the measurement of TRH and TRH-Gly cross-reactive material in crude extracts constitutes an accurate determination of the true levels of the two peptides. When the TRH and TRH-Gly from the RP-HPLC

\footnotetext{
${ }^{2}$ Since the analysis of 360 fetal hypothalami was not feasible, a single determination was performed. However, since the average SEM in all other culture extract RIA analyses was $8.5 \%$, and the maximum error observed was $23 \%$, the $300 \%$ changes in both TRH and TRHI-Gly levels as a function of ascorbate supplementation are clearly greater than the inherent error in these experiments.
} 
analysis (Fig. 6) were treated further with pyroglutamate aminopeptidase, there was a dramatic drop in the cross-reactive material in both peaks. This indicated that both immunoactive peaks contained material possessing an $\mathrm{NH}_{2}$-terminal pyroglutamate residue that was required for cross-reactivity. Specificity tests for both the TRH and TRH-Gly antisera indicated the requirement for the $\mathrm{NH}_{2}$-terminal pyroglutamate residue (Fig. 5).

Further analysis of TRH- and TRH-Gly-related peptides using RP-HPLC in a heptafluorobutyric acid/acetonitrile solvent system, and using cation-exchange HPLC in an ammonium formate solvent system, verified that the immunoreactive TRH and TRH-Gly comigrated with synthetic standard peptides (not shown).

\section{Discussion}

$\alpha$-Amidation is a common posttranslational modification among peptides and is required in most cases for optimal bioactivity (Mains et al., 1983). Thus, it is important to elucidate the mechanism of $\alpha$-amidation in neurons, since it is likely to be an important regulatory point in neuropeptide biosynthesis. In this paper we have presented evidence that the $\alpha$-amidation of TRH in hypothalamic cells is ascorbate-dependent and that a $\mathrm{COOH}$ terminally glycine-extended form of TRH (pyro-Glu-His-ProGly; TRH-Gly) is a likely intermediate in the biosynthetic pathway for this neuropeptide. These present results extend our previous studies of $\alpha \mathrm{MSH}$ biosynthesis in the intermediate pituitary and suggest that the $\alpha$-amidation of many, if not all, neuro- and endocrine peptides is dependent on ascorbate. It is also apparent that in both endocrine and neuronal cells similar $\alpha$-amidation enzyme activities are responsible for the conversion of $\mathrm{COOH}$-terminally glycine-extended peptides to $\mathrm{COOH}-$ terminally $\alpha$-amidated molecules.

Initial experiments with cultured hypothalamic cells demonstrated that TRH content in the cultures was increased by the addition of ascorbate to the medium (Fig. 1). The cultures were then maintained in medium supplemented with various amounts of ascorbate and demonstrated a half-maximal increase in TRH content at about $20 \mu \mathrm{M}$ ascorbate (Fig. 2). This half-maximal level of ascorbate is consistent with the 20-50 $\mu \mathrm{M}$ levels of the cofactor found in the circulation (Hornig, 1975), as well as the $K_{\mathrm{m}}$ values of the ascorbate transport system in anterior pituitary (P. P. Shields, T. R. Gibson, and C. C. Glembotski, unpublished observations) and adrenal medullary cells (Diliberto et al., 1983). In intermediate pituitary cultures, the conversion of COOH-terminally glycine-extended forms of $\alpha$ MSH to $\alpha$-amidated forms is also dependent on ascorbate with a half-maximal response at about $20 \mu \mathrm{M}$ ascorbate (Glembotski, 1984). Similar levels of ascorbate are required to support the dopamine $\beta$-hydroxylase-mediated conversion of dopamine to norepinephrine in sympathetic cervical ganglion cells in culture (Mains and Patterson, 1973a, b). The pharmacological profile of the increase in hypothalamic culture TRH content also demonstrated the requirement for the reduced form of ascorbate (Fig. 3). D-Isoascorbate, a stereoisomer of ascorbate, was capable of supporting the increase in TRH content; this has also been demonstrated for $\alpha \mathrm{MSH}$ formation by intermediate pituitary cells (Glembotski, 1984). Thus, the cultured hypothalamic cells are responsive to ascorbate forms and levels consistent with other well-characterized ascorbate-dependent cellular functions.

To demonstrate more directly that ascorbate facilitates the $\alpha$-amidation of TRH by way of a COOH-terminally glycineextended intermediate, an antibody was raised to TRH-Gly. Immunoreactive TRH-Gly was detected in hypothalamic tissue and culture extracts; RP- and ion-exchange-HPLC analysis further verified the identity of TRH-Gly immunoactivity in hypothalamic extracts. Further evidence that TRH-Gly is an intermediate in TRH formation was obtained from experiments using hypothalamic cultures maintained with and without ascorbate (see Results). The levels of TRH and TRH-Gly immunoreactivity responded diametrically: Cultures supplemented with ascorbate contained about 3 -fold more TRH and 3-fold less TRH-Gly than those maintained in medium lacking ascorbate. Since these changes are much greater than the average error of all similar experiments (see footnote, p. 1800), this result suggests that ascorbate is required for the conversion of endogenous TRH-Gly to TRH in cultured hypothalamic cells.

Immunoreactive TRH and TRH-Gly levels were also determined in hypothalamic extracts derived from rats of various ages (Table 2). The ratio of 'TRH/TRH-Gly immunoactivities increased as a function of animal age. The similarity in the TRH/ TRH-Gly immunoreactivity ratio between fetal hypothalamic extracts (TRH/TRH-Gly = 1.2) and extracts of fetal hypothalamic cells maintained in culture with ascorbate (TRH/TRHGly $=0.94$ ) indicated that the cofactor supplementation in vitro closely simulated in vivo conditions. The increase in the TRH/ TRH-Gly immunoactivity ratio as a function of age may be due to a corresponding developmental increase in PAM activity as a result of either a change in enzyme-specific activity or a change in the responsiveness of hypothalamic cells to ascorbate.

It has been observed that extra-hypothalamic TRH levels change in different ways during development. For example, in fetal rats ( $21 \mathrm{~d}$ gestation) the olfactory bulbs contain no detectable TRH (Lamberton et al., 1984), yet in the adult as much as $1.8 \mathrm{ng}$ TRH has been localized to this CNS structure (Kreider et al., 1981; Lamberton et al., 1984). One possibility is that fetal olfactory bulbs contain TRH-Gly but are unable to convert it to TRH. We were unable to detect either TRH or TRH-Gly immunoactivity in extracts of fetal olfactory bulb. Thus, if fetal olfactory bulb cells express the gene for TRH, the lack of TRH and TRH-Gly indicate that posttranslational processing of TRH precursors is not complete. Also, neonatal rat pancreas has been reported to contain more TRH than the neonatal rat hypothalamus. However, unlike hypothalamic TRH levels, pancreatic TRH levels decline from birth throughout $28 \mathrm{~d}$ of age (Lamberton et al., 1984). We were able to detect TRH in fetal ( $20 \mathrm{~d}$ gestation) pancreas in quantities similar to fetal hypothalamus, but, unlike the hypothalamus, there was no detectable TRHGly (not shown). This may indicate that in the pancreas at 20 $\mathrm{d}$ gestation, the gene for TRH is no longer expressed, and all precursor forms of the peptide have been converted to the product. These interesting tissue-specific differences in the developmental profile of TRH provide a unique model system with which to characterize the various factors responsible for the cxpression of the samc pcptide (TRH) in neuroendocrine (hypothalamus), neuronal (olfactory), and endocrine (pancreatic) cells.

An important approach to further studies on TRH biosynthesis will involve the incorporation of radiolabeled amino acids into TRH-rclated peptides. Such studies should be performed with cultured cells in order to facilitate quantitative pulse-chase studies for verification of product-precursor relationships. The incorporation of labeled amino acids into authentic TRH by cultured hypothalamic cells obviously requires the continued formation of the peptide in vitro. The present data support the notion that without ascorbate in the medium, very little, if any, incorporation would take place. For example, intermediate pituitary cells maintained in culture without ascorbate lose the ability to form $\alpha$-amidated $\alpha \mathrm{MSH}$ with a half-time of about 15 hr (Eipper et al., 1983a; Glembotski et al., 1983); these cells produce the $\mathrm{COOH}$-terminally glycine-extended form of the peptide as an alternate end product. Further studies involving the strategic use of ascorbate and the TRH-Gly antiserum described in this report will be most important in biosynthetic labeling studies designed to demonstrate the precursor-product relationship between TRH-Gly and TRH. 


\section{References}

Bassiri, R. M., and R. D. Utiger (1972) The preparation and specificity of antibody to thyrotropin releasing hormone. Endocrinology $90: 722$ 727.

Bassiri, R. M., and R. D. Utiger (1974) Thyrotropin-releasing hormone in the hypothalamus of the rat. Endocrinology 94: 188-197.

Bennett, H. P. J., C. A. Browne, and S. Solomon (1981) The purification of the two major forms of rat pituitary corticotropin using only reversed-phase liquid chromatography. Biochemistry 20:4530-4538.

Bloom, F. E. (1983) The endorphins: A growing family of pharmacologically pertinent peptides. Annu. Rev. Pharmacol. Toxicol. 23: 151-170.

Boler, R. M., F. Enzman, K. Folkers, C. Y. Bowers, and A. V. Schally (1969) The identity of chemical and hormonal properties of the thyrotropin releasing hormone and pyroglutamyl-histidyl-proline amide. Biochem. Biophys. Res. Commun. 37: 705-710.

Bradbury, A. F., M. D. A. Finnie, and D. G. Smyth (1982) Mechanism of C-terminal amide formation by pituitary enzymes. Nature 298 : 686-688.

Brownstein, M. J. (1983) Biosynthesis of vasopressin and oxytocin. Annu. Rev. Physiol. 45: 129-135.

Brownstein, M. J., M. Palkovits, J. M. Saavedra, R. M. Bassiri, and R. D. Utiger (1974) Thyrotropin releasing hormone in specific nuclei of rat brain. Science $185: 267-269$.

Burgus, R., T. F. Dunn, D. Desiderio, and R. G. Guillemin (1969) Structure moleculaire du facteur hypothalamique hypophysiotrope TRH d'origine ovine: Mise en evidence pour spectrometrie de masse

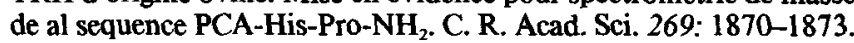

Canick, J. A., D. E. Vaccaro, K. J. Ryan, and S. E. Leeman (1977) The aromatization of androgens by primary monolayer cultures of fetal rat hypothalamus. Endocrinology 100: 250-253.

Court, J. A., A. I. Smith, J. R. McDermott, J. A. Biggins, and J. A. Edwardson (1983) Failure of gel filtration and HPLC purification to increase levels of immunoreactive TRH in rat brain extracts. Peptides 4: 585-587.

Diliberto, E. J., Jr., G. D. Heckman, and A. J. Daniels (1983) Characterization of ascurbic acid transport by adrenomedullary chromaffin cells. J. Biol. Chem. 258: 12886-12894.

Douglass, J., O. Civelli, and E. Herbert (1984) Polyprotein gene expression: Generation of diversity of neuroendocrine peptides. Annu. Rev. Biochem. 53: 665-715.

Eipper, B. A., C. C. Glembotski, and R. E. Mains (1983a) Selective loss of $\alpha$-melanotropin-amidating activity in primary cultures of rat intermediate pituitary cells. J. Biol. Chem. 258: 7292-7298.

Eipper, B. A., R. E. Mains, and C. C. Glembotski (1983b) Identification in pituitary tissue of a peptide $\alpha$-amidation activity that acts on glycine-extended peptides and requires molecular oxygen, copper, and ascorbic acid. Proc. Natl. Acad. Sci. USA 80: 5144-5148.

Eipper, B. A., R. E. Mains, and C. C. Glembotski (1985) Peptide $\alpha$-amidation: Cellular and enzymatic studies. In Biogenetics of Neurohormonal Peptides, R. Hakanson and J. Thorell, eds., pp. 187-209, Academic, New York.

Emeson, R. B. (1984) Hypothalamic peptidyl-glycine $\alpha$-amidating monooxygenase: Preliminary characterization. J. Neurosci. 4: 2604 2613.

Faivre-Bauman, A., A. Nemeskeri, C. Tougard, and A. Tixier-Vidal (1980) Immunological evidence for thyroliberin (TRH) neurons in primary cultures of fetal mouse brain cells. Ontogenic aspects. Brain Res. 185: 289-304.

Glembotski, C. C. (1984) The $\alpha$-amidation of $\alpha$-melanocyte stimulating hormone in intermediate pituitary requires ascorbic acid. $\mathrm{J}$. Biol. Chem. 259: 13041-13048.

Glembotski, C. C. (1985) Further characterization of the peptidyl $\alpha$ amidating enzyme in rat anterior pituitary secretory granules. Arch. Biochem. Biophys. 241: 673-683.

Glembotski, C. C., B. A. Eipper, and R. E. Mains (1983) Adrenocorticotrophin (1-14) OH-related molecules in primary cultures of rat intermediate pituitary cells. J. Biol. Chem. 258: 7299-7304.
Gomez, S., C. di Bello, L. T. Hung, R. Genet, J.-L. Morgat, P. Fromageot, and P. Cohen (1984) C-terminal amidation of neuropeptide: Gly-Lys-Arg extension an efficient precursor of C-terminal amide. FEBS Lett. 167: 160-164.

Hökfelt, T., O. Johansson, and M. Goldstein (1984) Chemical anatomy of the brain. Science 225: 1326-1334.

Hornig, D. (1975) Distribution of ascorbic acid, metabolites and analogues in man and animals. Ann. NY Acad. Sci. 258: 103-117.

Husain, I., and S. S. Tate (1983) Formation of the COOH-terminal amide group of thyrotropin releasing factor. FEBS Lett. 152: 277281.

Iverson, L. L. (1983) Nonopioid neuropeptides in mammalian CNS. Annu. Rev. Pharmacol. Toxicol. 23: 1-27.

Jackson, I. M. D. (1982) Thyrotropin-releasing hormone. N. Engl. J. Med. 306: 145-155.

Kizer, J. S., W. H. Busby, Jr., C. Cottle, and W. W. Youngblood (1984) Glycine directed peptide amidation: Presence in rat brain of two enzymes which convert P-Glu-His-Pro-Gly-OH into P-Glu-His-Pro$\mathrm{NH}_{2}$ (thyrotropin-releasing hormone). Proc. Natl. Acad. Sci. USA 81: 3228-3232.

Kreider, M. S., A. Winokur, and N. R. Krieger (1981) The olfactory bulb is rich in TRH immunoreactivity. Brain Res. 217: 69-77.

Krieger, D. T. (1983) Brain peptides: What, where and why? Science 222: 975-985.

Lamberton, R. P., R. M. Lechnan, and I. M. D. Jackson (1984) Ontogeny of thyrotropin-releasing hormone and histidyl proline diketopiperazine in the rat central nervous system and pancreas. Endocrinology 115: 2400-2405.

Mains, R. E., and B. A. Eipper (1979) Synthesis and secretion of corticotropins, melanotropins, and endorphins by rat intermediate pituitary cells. J. Biol. Chem. 254: 7885-7894.

Mains, R. E., and P. H. Patterson (1973a) Primary cultures of dissociated sympathetic neurons. I. Establishment of long-term growth in culture and studies of differentiated properties. J. Cell Biol. 59. 329-345.

Mains, R. E., and P. H. Patterson (1973b) Primary cultures of dissociated sympathetic neurons. II. Initial studies on catacholamine metabolism. J. Cell Biol. 59: 346-360.

Mains, R. E., B. A. Eipper, C. C. Glembotski, and R. M. Dores (1983) Strategies for the biosynthesis of bioactive peptides. Trends Ncurosci. 6: 229-235.

McKelvy, J. F. (1974) Biochemical neuroendocrinology. I. Biosynthesis of thyrotropin releasing hormone (TRH) by organ cultures of mammalian hypothalamus. Brain Res. 65: 489-502.

McKelvy, J. F. (1983) Thyrotropin-releasing hormone biosynthesis. In Thyrotropin Releasing Hormone, E. C. Griffiths and G. W. Bennett, eds., pp. 51-59, Raven, New York.

McKelvy, J. F., M. Sheridan, S. Joseph, C. H. Phelps, and S. Perrie (1975) Biosynthesis of thyrotropin-releasing hormone in organ cultures of the guinea pig median eminence. Endocrinology 97: 908918

Reichlin, S., and M. Mitnick (1971) Thyrotropin-releasing hormone: Biosynthesis by rat hypothalamic fragments in vitro. Science 172 : 1241-1243.

Richter, K., E. Kawashima, R. Egger, and G. Kreil (1984) Biosynthesis of thyrotropin releasing hormone in the skin of Xenopus laevis: Partial sequence of the precursor deduced from cloned cDNA. EMBO J. 3: 617-621.

Rupnow, J., P. Hinkle, and J. E. Dixon (1979) A macromolecule which gives rise to thyrotropin releasing-hormone. Biochem. Biophys. Res. Commun. 89: 721-728.

Tolbert, B. M., and J. B. Ward (1982) Dehydroascorbic acid. In Ascorbic Acid: Chemistry, Metabolism, and Uses, P. A. Seib and B. A. Tolbert, eds., pp. 101-123, Am. Chem. Soc., Washington, DC.

Winokur, A., and R. D. Utiger (1974) Thyrotropin-releasing hormone: Regional distribution in rat brain. Science 185: 265-267. 